\title{
Pelatihan Penulisan Artikel di Jurnal Nasional Terakreditasi dan Internasional Bereputasi Bagi Mahasiswa Magister Pendidikan IPA Universitas Mataram
}

\author{
Aris Doyan ${ }^{1,2^{*}}$, Susilawati ${ }^{1,2}$, Ahmad Harjono ${ }^{1,2}$, \\ ${ }^{1}$ Magister Pendidikan IPA, Pasca Sarjana, Universitas Mataram, Mataram, Lombok, Nusa Tenggara Barat, Indonesia \\ 2Program Studi Pendidikan Fisika, Fakultas Keguruan dan Ilmu Pendidikan, Universitas Mataram, Mataram, Lombok, Nusa Tenggara \\ Barat, Indonesia \\ ${ }^{3}$ Mahasiswa Program Studi Pendidikan Fisika, Fakultas Keguruan dan Ilmu Pendidikan, Universitas Mataram, Mataram, Lombok, Nusa \\ Tenggara Barat, Indonesia
}

\section{DOI: $\underline{10.29303 / \text { ujcs.v2i4.133 }}$}

\section{Article Info}

Received: October $26^{\text {th }}, 2021$

Revised: November $8^{\text {th }}, 2021$

Accepted: November 14th, 2021

\begin{abstract}
Article writing training in accredited and internationally reputable national journals for master of science education students has been conducted online using zoom meetings. This training activity aims to train master of science education students to be able to publish work from their research results in accredited national journals and in reputable journals indexed scopus. The event was attended by 16 students during seven zoom meeting meetings and using WhatApp group. The results of this journal surgery show that students have been able to submit, review and repair and publish their articles in the journal jppipa.unram.ac.id.

Kata Kunci: National Journal; Accredited; Reputable international

Abstract: Pelatihan Penulisan artikel di jurnal nasional terakreditasi dan internasional bereputasi untuk mahasiswa Magister Pendidikan IPA telah dilakukan secara daring menggunakan zoom meeting. Kegiatan pelatihan ini bertujuan untuk melatih mahasiswa magister IPA untuk dapat mempublikasikan karya dari hasil penelitiannya di jurnal nasional terakreditasi dan di jurnal bereputasi terindek scopus. Kegiatan di hadiri oleh 16 orang mahasiswa selama tujuh kali pertemuan zoom meeting dan menggunakan WhatApp group. Hasil bedah jurnal ini menunjukan mahasiswa telah dapat melakukan proses mensubmit, mereview dan memperbaiki serta mempublikasikan artikelnya di jurnal jppipa.unram.ac.id

Keywords: Jurnal Nasional; Terakreditasi; Internasional bereputasi
\end{abstract}

Citation: Doyan, A., Susilawati, S., \& Harjono, A. (2021). Pelatihan Penulisan Artikel di Jurnal Nasional Terakreditasi dan Internasional Bereputasi Bagi Mahasiswa Magister Pendidikan IPA Universitas Mataram, (2021). Unram Journal of Community Service. 2(4). 95-98. doi. https://doi.org/10.29303/ujcs.v2i4.133

\section{Pendahuluan}

Salah satu sebab minimnya jumlah publikasi artikel di Indonesia adalah kurang tingginya produktivitas karya ilmiah di tingkat pendidikan Pascasarjana. Karya ilmiah merupakan laporan tertulis yang memenuhi kaidah dan etika keilmuan. Karya ilmiah tersebut berupa laporan penelitian, makalah seminar, makalah simposium, dan artikel ilmiah. Artikel ilmiah dapat diangkat dari hasil penelitian, hasil pemikiran dan kajian pustaka, serta hasil pengembangan proyek yang dapat dipublikasikan dalam jurnal, prosiding dan majalah ilmiah (Adhikara, 2014).

Karya tulis ilmiah merupakan salah satu luaran dan outcome yang menjadi syarat kelulusan bagi mahasiswa. Hal ini sejalan dengan regulasi dari Dikti (2012) yang mengatur kelulusan di masing-masing strata tingkat pendidikan, bahwa strata satu harus menghasilkan karya ilmiah yang bisa dideseminasikan 
dalam publikasi ilmiah. Selain itu, mahasiswa Pascasarjana wajib mempublikasikan hasil risetnya pada jurnal nasional terakreditasi bagi mahasiswa magister (S2) dan publikasi pada jurnal Internasional bereputasi bagi mahasiswa program doktor (S3). Dengan demikian, menulis karya ilmiah merupakan syarat mutlak bagi mahasiswa yang akan lulus dari perguruan tinggi dan sebagai wujud pelaksanaan tridharma perguruan tinggi. Namun persyaratan tersebut terkadang dianggap sebagai tugas berat dan sesuatu yang menakutkan bagi mahasiswa. Hal ini disebabkan karena kompetensi dalam menyusun karya ilmiah masih kurang dan mahasiswa bingung dalam memilih jurnal yang teakreditasi dan bereputasi. Selain itu, mahasiswa terkadang takut untuk mempublikasikan karya ilmiahnya di jurnal ilmiah ber ISSN karena khawatir karya tersebut terindikasi plagiat.

Berdasarkan analisis situasi di atas, maka permasalahan yang dirumuskan adalah bagaimana meningkatkan kemampuan mahasiswa Magister Pendidikan IPA UNRAM dalam menulis artikel di jurnal nasional terakreditasi dan internasional bereputasi?

\section{Metode}

Menanggapi permasalahan yang mengakibatkan kurangnya kemampuan mahasiswa magister dalam menulis artikel di jurnal nasional terakreditasi dan internasional bereputasi, maka permasalahan ini dapat diselesaikan dengan cara memberikan pelatihan kepada mahasiswa Magister Pendidikan IPA UNRAM.

Beberapa tahapan yang akan dilalui dalam penyelesaian masalah ini yaitu tahap persiapan (plan), tahap pelaksanaan, dan tahap evaluasi. Secara sederhana tahapan ini direpresentasikan dalam gambar 1.

\section{Tahapan Persiapan}

Pada tahap persiapan dilakukan observasi terhadap mahasiswa Magister Pendidikan IPA UNRAM, guna untuk mengidentifikasi permasalahan yang dihadapi dalam penulisan artikel di jurnal nasional terakreditasi dan internasional bereputasi. Hasil observasi ditemukan bahwa mahasiswa Magister Pendidikan IPA UNRAM kurang mendapatkan informasi mengenai jurnal terakreditasi nasional dan bereputasi internasional, sehingga mereka tidak mengetahui cara penulisan artikel di jurnal terakreditasi nasional dan bereputasi internasional tersebut. Salah satu upaya untuk menyelesaikan masalah tersebut adalah dengan dilakukan pelatihan kepada mahasiswa Magister Pendidikan IPA UNRAM agar dapat menulis artikel di jurnal nasional terakreditasi dan internasional bereputasi dengan baik dan benar, sehingga artikel yang ditulis tersebut dapat diterima di jurnal nasional terakreditasi dan internasional bereputasi.

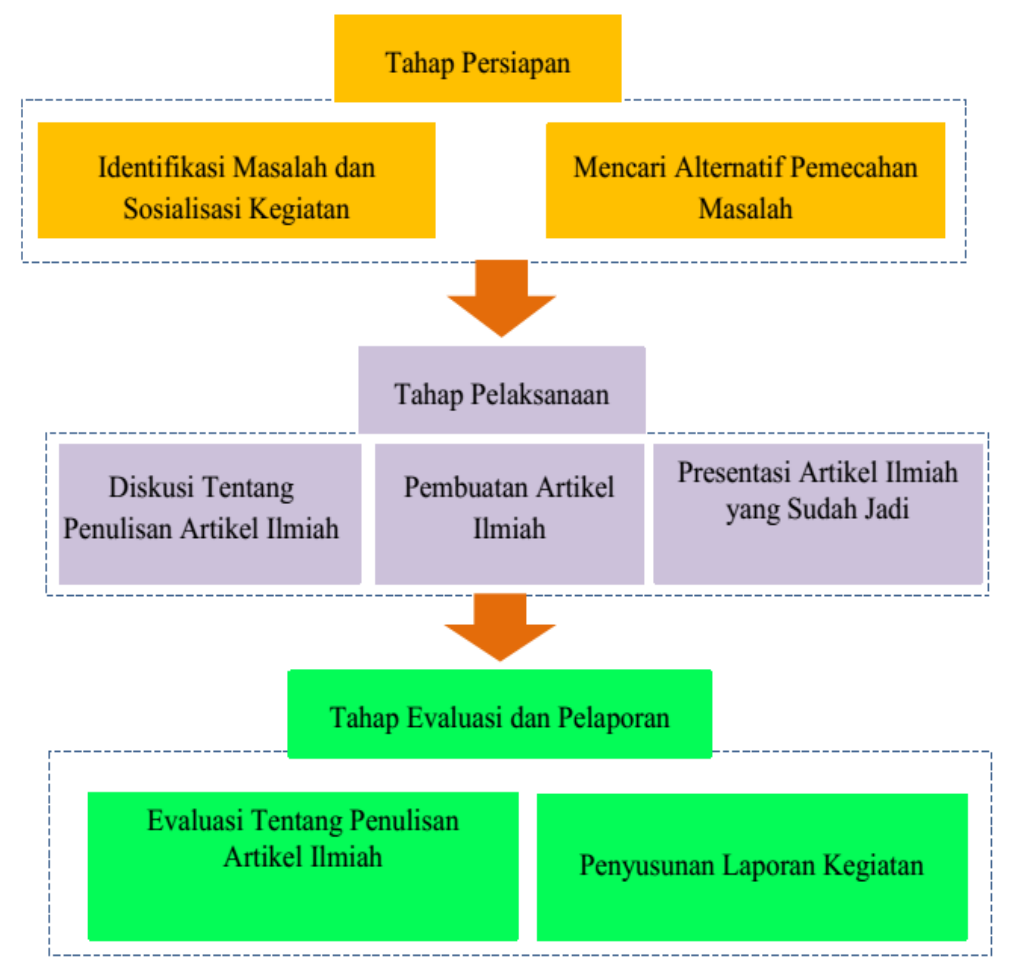

Gambar 1. Kerangka Pelaksanaan Kegiatan Pengabdian 


\section{Tahapan Pelaksanaan}

Pada tahap pelaksanaan ini merupakan tindak lanjut untuk menyelesaikan permasalahan yang dialami mahasiswa Magister Pendidikan IPA UNRAM tentang penulisan artikel, yaitu dengan dilaksanakan pelatihan langsung mengenai cara penulisan artikel yang baik dan benar, sehingga dapat diterima di jurnal terakreditasi nasional dan bereputasi internasional. Pada tahapan ini, mahasiswa yang telah membuat artikel akan diminta untuk mempresentasikan artikel yang telah dibuat selama proses pelatihan berlangsung. Proses pelatihan penulisan artikel dilakukan dengan berpedoman pada templet di di jurnal terakreditasi nasional dan bereputasi internasional.

\section{Tahapan Evaluasi dan Pelaporan}

Evaluasi hasil pelatihan dilakukan secara langsung dengan menilai hasil penulisan artikel yang telah dibuat oleh mahasiswa Magister Pendidikan IPA UNRAM. Pelaporan kegiatan pengabdian dilakukan dengan menyusun laporan pelatihan menulis artikel di jurnal nasional terakreditasi dan internasional bereputasi pada mahasiswa Magister Pendidikan IPA UNRAM.

\section{Hasil dan Pembahasan}

Pelatihan diberikan kepada 16 orang mahasiswa magister Pendidikan IPA tahun ajaran 2020/2021.
Seluruh peserta pelatihan dipandu melalui aplikasi zoom meetings dan whatApp Group. Peserta kegiatan tertera pada Tabel 1.

Tabel 1. Daftar Nama Peserta Pelatihan Penulisan Artikel Ilmiah

\begin{tabular}{ll}
\hline No. & Nama Peserta \\
\hline 1 & Mujitahid \\
2 & Via Monica Devi \\
3 & Ferniawan \\
4 & Moammar Qadafi \\
5 & Istiqomah \\
6 & Rika Ratnasari \\
7 & Bung Ashabul Qahfi \\
8 & Muhammad Yusril Yusup \\
9 & Anak Agung Ayu Diah Kusumadewi \\
10 & Hendra Susana Putra \\
11 & Ulfah Nurkhaeroni \\
12 & M. Akhyar Rosyidi \\
13 & Sekar Partiwi \\
14 & Rizal Umami \\
15 & Bq. Fitri Rahmayanti \\
16 & Halimatusa'adiah \\
\hline
\end{tabular}

Materi yang disampaikan kepada mahasiswa dijelaskan melalui kegiatan pelatihan yang diberikan oleh pemateri/dosen secara online. Pelatihan yang disampaikan meliputi tahapan membedah jurnal dan memberikan contoh-contoh artikel yang sudah terbit di jurnal nasional terakreditasi dan internasional bereputasi. Jurnal nasional dan internasional yang telah di bedah seperti tabel 2 .

Tabel 2. Nama Jurnal Nasional dan Internasional yang telah di bedah

\begin{tabular}{lll}
\hline No & $\begin{array}{l}\text { Nama Jurnal Nasional dan internasional } \\
\text { terakreditasi }\end{array}$ & Website \\
\hline 1 & JurnalPenelitian Pendidikan IPA & https://jppipa.unram.ac.id/index.php/jppipa/search \\
\hline 2 & Jurnal Pendidikan Fisika dan Tehnologi & https://jurnalfkip.unram.ac.id/index.php/JPFT \\
3 & Jurnal Piar & https://jurnalfkip.unram.ac.id/index.php/JPM/index \\
4 & Journal of Science Education and Science & $\begin{array}{l}\text { https://jppipa.unram.ac.id/index.php/jossed/issue/view/45 } \\
\text { https://journal.unnes.ac.id/nju/index.php/jpii/about }\end{array}$ \\
5 & Jurnap Pendidikan IPA Indonesia & https://www.ijsr.net/?gclid=CjOKCQiA-K2MBhC-ARIsAMtLKRvVvDka- \\
6 & International Journal of Science and Research & 95Ri1032l_PkpxJ_HeIqOPxQ4Y4xaRIuaJNExJCP0zPfMQaApUGEALw_wcB \\
& & https://www.mdpi.com/about/journals \\
\hline
\end{tabular}

Proses pembedahan meliputi bagaimana proses submit, review dan published. Setelah mahasiswa berhasil membedah jurnal tahapan berikutnya di lanjutkan dengan bagaimana mahasiswa membuat artikel di jurnal nasional dan internasional.
Hasil pelatihan ini telah mempublikasi beberapa artikel di jurnal internasional tidak bereputasi di jurnal jossed. Artikel yang berhasil di publikasi tertera pada tabel 2.

Tabel. Artikel hasil pelatihan yang telah berhasil di publikasi di jurnal jossed

\begin{tabular}{|c|c|c|}
\hline $\mathrm{No}$ & Judul Artikel & Web site \\
\hline 1 & $\begin{array}{l}\text { Effectiveness of Problem Based Learning Device Development to } \\
\text { Improve Generic Science Skills }\end{array}$ & $\begin{array}{l}\text { https://jppipa.unram.ac.id } \\
\text { /index.php/jossed/article/view/919 }\end{array}$ \\
\hline 2 & $\begin{array}{l}\text { Xbee Pro S1 Based Wireless Data Acquisition System for Landslide } \\
\text { Monitoring }\end{array}$ & $\begin{array}{l}\text { https://jppipa.unram.ac.id } \\
\text { /index.php/jossed/article/view/918 }\end{array}$ \\
\hline 3 & $\begin{array}{l}\text { Physicochemical Properties Of Used Cooking Oil Purified Using } \\
\text { Shallot (Allium Cepa L.) Pell Adsorbent }\end{array}$ & $\begin{array}{l}\text { https://jppipa.unram.ac.id } \\
\text { /index.php/jossed/article/view/ } 920\end{array}$ \\
\hline
\end{tabular}


Berdasarkan hasil pelatihan dari mahasiswa magister Pendidikan IPA tersebut kegiatan ini merupakan kegiatan yang dianggap sangat relevan terhadap kebutuhan mahasiswa yang akan mengikuti perkuliahan dan pembuatan tesis dan penulisan karya ilmiah dalam bentuk publikasi artikel di jurnal nasional dan internasional.

\section{Kesimpulan}

Kegiatan Pelatihan Penulisan Artikel di Jurnal Nasional Terakreditasi dan Internasional Bereputasi Bagi Mahasiswa Magister Pendidikan IPA Universitas Mataram mampu menambah wawasan pengetahuan, dan keterampilan mahasiswa dalam membedah jurnal nasional dan jurnal internasional dalam bentuk pembuatan, submit, review, dan published artikel.

\section{Ucapan Terimakasih}

Penulis mengucapkan terima kasih kepada Pendanaan PNBP Pascasarjana Universitas Mataram yang telah memberi dukungan finansial terhadap pengabdian ini.

\section{Kepustakaan}

Adhikara, M. A., Handayani, S., Jumono, S., \& Darmansyah. (2014). Pelatihan Penyusunan Artikel Publikasi Ilmiah Pada Mahasiswa Perguruan Tinggi di Jakarta Barat. Jurnal Abdimas, 1(1), 41-52.

Alam, S. (2015). Penulisan Artikel Ilmiah Untuk Publikasi Ilmiah Melalui Jurnal. E-Buletin, (April), 1-19

Fernando, A., Sarkity, D., \& Putri, A. N. (2021) Pelatihan Pembuatan Video Pembelajaran Menggunakan Open Broadcaster Software (OBS) Studio untuk Guru SMAN 1 Bintan Timur. Jurnal Anugerah. 3(1), 1-14

Gusmania, Y. \& Wulandari, T. (2018). Efektivitas Penggunaan Media Pembelajaran Berbasis Video Terhadap Pemahaman Konsep Matematis Siswa. PYTHAGORAS. 7(1), 61 - 67.

Ismail, I., Hasan, H., \& Musdalifah, M. (2018). Pengembangan Kompetensi Mahasiswa Melalui Efektivitas Program Magang Kependidikan. Edumaspul: Jurnal Pendidikan, 2(1), 124-132.

Nurwahidah, C.D., Zaharah, \& Sina, I. (2021). Media Video Pembelajaran Dalam Meningkatkan Motivasi Dan Prestasi Mahasiswa. Rausyan Fikr :Jurnal Pemikiran dan Pencerahan. 17(1), 118-127

Ratna K, D. A. S., Prastikawati, E. F., \& Setyorini, A. (2012). Pelatihan Penulisan Artikel Ilmiah Guru Bahasa Inggris SMA di Kota Semarang (Sebagai Pencapaian KEPMENPAN Nomor 16 Tahun
2009 tentang Jabatan Fungsional Guru Dan Angka Kreditnya).

Usman, A.A. \& Ma'ruf. (2019). Analisis Pelaksanaan Pembelajaran Dalam Program Praktek Lapangan Mahasiswa Pendidikan Fisika Stkip Kie Raha Ternate. JPF. 1(2), 109-120.

Prastiti, T.D et al. (2020). Pelatihan Pembuatan Video Pembelajaran Berbasis Youtube Bagi Guru- Guru Sd Di Kabupaten Sidoarjo. Seminar Nasional Pengabdian Kepada Masyarakat Universitas Terbuka. 19 Oktober

Yunita, E. \& Suprapto, N. (2021). Analisis Kelayakan Video Pembelajaran Fisika Berbasis Platform Youtube Pada Materi Usaha dan Energi. IPF : Inovasi Pendidikan Fisika. 10(1), 21-31. 